\title{
PROBLEMY ODWZOROWANIA RZECZYWISTYCH CHARAKTERYSTYK ZBIORNIKÓW PALIWA SAMOLOTU W WARUNKACH LABORATORYJNYCH
}

\begin{abstract}
Informacja o ilości paliwa w zbiornikach statku powietrznego jest parametrem szczególnie istotnym dla bezpieczeństwa lotu. Ze względu na złożone kształty i liczbę zbiorników dla zapewnienia dokładnego pomiaru konieczny jest rozbudowany system o dużym stopniu skomplikowania konstrukcji. W celu kontroli parametrów paliwomierza niezbędne jest stanowisko laboratoryjne, wiernie odwzorowujące rzeczywiste charakterystyki zbiorników paliwa statku powietrznego, dla którego urządzenie zostało zaprojektowane. W pracy opisano problemy, jakie musieli rozwiązać konstruktorzy stanowiska pomiarowego dla paliwomierzy PPM-1 eksploatowanych w samolotach typu M-28. Przedstawiono zależności pomiędzy poszczególnymi elementami stanowiska a nadajnikami instalowanymi w rzeczywistych zbiornikach samolotu i ich połączeniem z pokładowym systemem pomiaru i wskazań paliwa. Omówiono pokrótce zasady pomiaru masy paliwa w zbiornikach i sposób wzorcowania kompletów paliwomierzy na stanowisku, a także czynniki mogące zdestabilizować pomiary lub ograniczyć ich dokładność.
\end{abstract}

Słowa kluczowe: zbiornik paliwa samolotu, paliwomierz, bezpieczeństwo lotu

\section{Wprowadzenie}

Zbiorniki paliwa na statkach powietrznych są tak konstruowane, aby maksymalnie wykorzystywały wolną przestrzeń, a jednocześnie nie miały niekorzystnego wpływu na stabilność tych statków [1]. Umieszcza się je zarówno w kadłubach samolotów i śmigłowców, jak i w skrzydłach samolotów. Wymiary zbiorników i ich konstrukcja muszą być tak dobrane, aby możliwe było ograni-

${ }^{1}$ Zbigniew Mrotek, Instytut Lotnictwa, al. Krakowska 110/114, 02-256 Warszawa, e-mail: mrotek@ilot.edu.pl

${ }^{2}$ Marek Młynarczyk, Instytut Lotnictwa, al. Krakowska 110/114, 02-256 Warszawa, e-mail: młynarczyk@ilot.edu.pl

3 Autor do korespondencji/corresponding author: Zdzisław Szymański, Instytut Lotnictwa, al. Krakowska 110/114, 02-256 Warszawa, tel.: (22) 8460011, ext. 427, e-mail: szymanski@ilot.edu.pl 
czenie do minimum przemieszczania się paliwa podczas lotu. Ponieważ system zasilania w paliwo zawiera zwykle od kilku do kilkunastu wzajemnie połączonych zbiorników, paliwomierze muszą być urządzeniami konstruowanymi indywidualnie dla określonego typu statku powietrznego. System pomiaru ilości paliwa pozostającej $\mathrm{w}$ zbiornikach ma podstawowe znaczenie dla bezpieczeństwa lotu [2, 3]. Szczególne ważna jest dokładność wskazań w końcowej fazie lotu, gdy paliwo jest na wyczerpaniu, co pozwala ocenić maksymalny czas lotu do miejsca lądowania. Zachowanie sprawności paliwomierza ma ścisły związek $\mathrm{z}$ laboratoryjnym stanowiskiem pomiarowym, które jest wykorzystywane w celu uruchamiania, wzorcowania i kontroli paliwomierzy w trakcie ich eksploatacji. Problemy, z jakimi muszą się zmierzyć konstruktorzy stanowisk do wzorcowania i sprawdzania złożonych systemów paliwomierzy lotniczych, będą przedstawione na przykładzie paliwomierza PPM-1 (lub PPM-1B) do samolotu M-28 $[4,5]$.

\section{Paliwomierz pojemnościowy do M-28}

Na system paliwowy samolotu M-28 składa się osiem zbiorników rozmieszczonych symetrycznie w lewym i prawym skrzydle. Są to zbiorniki: główne rozchodowe, główne, dodatkowe skrzydłowe i centropłatu, opróżniane w trakcie lotu w kolejności odwrotnej do wymienionej. Ze względu na miejsce zabudowy zbiorniki te mają złożone kształty, są ,płytkie”, o dużej powierzchni, wypełniające skrzydła o rozpiętości około $20 \mathrm{~m}$. W celu pokrycia całego zakresu zmian poziomu paliwa i zminimalizowania wpływu wahań poziomu paliwa przemieszczającego się $\mathrm{w}$ trakcie lotu konieczne było zastosowanie 20 nadajników poziomu paliwa, montowanych bezpośrednio w górnej powierzchni skrzydeł.

Opracowany w Instytucie Lotnictwa paliwomierz masowy PPM-1 (i PPM-1B) $[4,5]$ (rys. 1.) działa na zasadzie pomiaru pojemności elektrycznej kondensatora w środowisku dielektrycznym. Pojemność każdego nadajnika zmienia się liniowo $\mathrm{w}$ funkcji poziomu paliwa. Zastosowane w paliwomierzu dwa dodatkowe nadajniki kompensują zmiany stałej dielektrycznej paliwa, a pośrednio wpływ jego temperatury i zanieczyszczeń, a sygnalizatory reszty paliwa tworzą niezależny układ ostrzegania o spadku ilości paliwa poniżej bezpiecznej rezerwy. Korzystając z wprowadzonych do pamięci cyfrowych charakterystyk wiążących poziom paliwa w każdym ze zbiorników z jego objętością, sygnały z nadajników pomiarowych i kompensacyjnych są przetwarzane w bloku elektroniki na informacje o masie paliwa w poszczególnych zbiornikach oraz o sumarycznej masie paliwa i wyświetlane na wskaźniku cyfrowo-analogowym i dwóch wskaźnikach cyfrowych dwukanałowych [5].

Paliwomierz PPM-1, dla którego jest przeznaczone stanowisko laboratoryjne, działa na zasadzie przetwarzania bieżącego poziomu paliwa, w którym są zanurzone jego nadajniki, na pojemność elektryczną. Każdy z nadajników pali- 


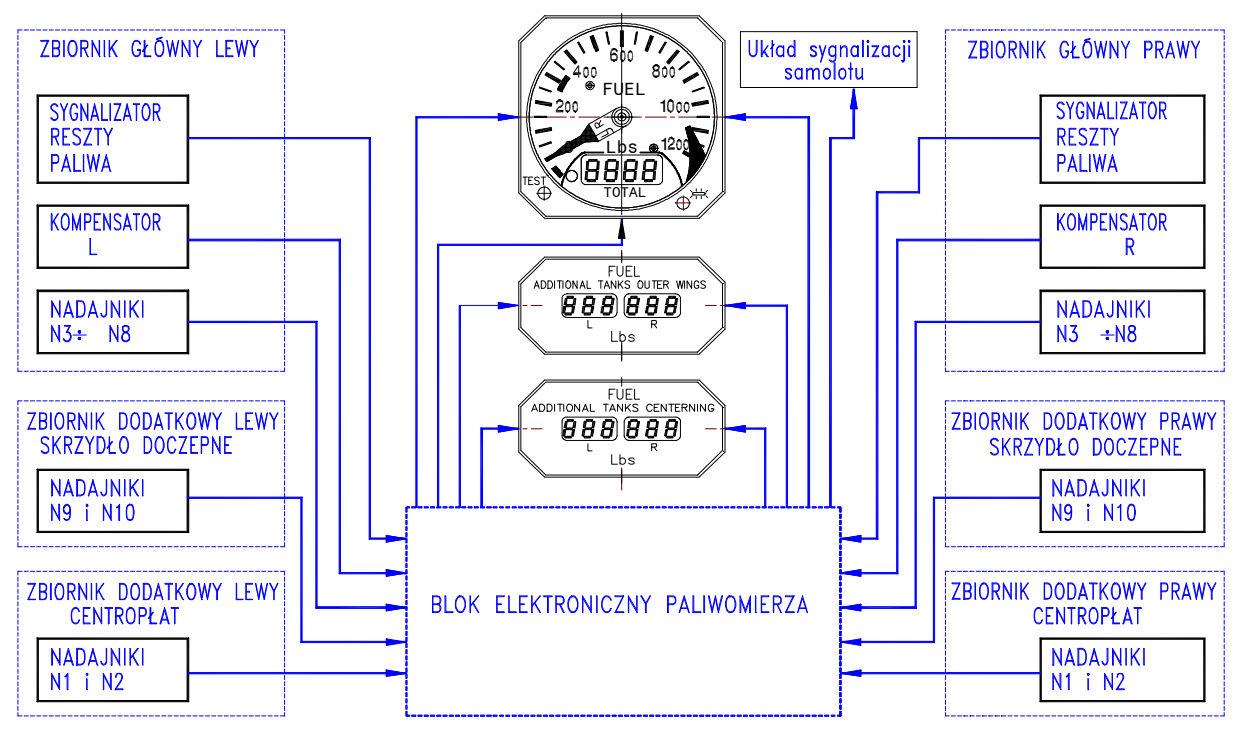

Rys. 1. Struktura paliwomierza PPM-1 (PPM-1B) przeznaczonego do samolotu M-28

Fig. 1. The structure of PPM-1 (PPM-1B) fuel gauge assigned to M-28 aircraft

womierza PPM-1 jest elementem biernym - kondensatorem elektrycznym, zbudowanym z trzech umieszczonych współosiowo cylindrów, z których dwa wewnętrzne tworzą okładki kondensatora pomiarowego, a zewnętrzny połączony $\mathrm{z}$ masą stanowi powierzchnię ekranującą. Pojemność $C$ kondensatora cylindrycznego, złożonego z dwóch współosiowych rur (rys. 2.) o średnicach $D 1, D 2$ i długości $L$, jest opisana następującą zależnością:

$$
C=\varepsilon_{r} \cdot C_{o}=\frac{\varepsilon_{r} \cdot \varepsilon_{o} \cdot 2 \pi L}{\ln (D 2 / D 1)},
$$

gdzie $\varepsilon_{r}$ jest przenikalnością dielektryczną materiału umieszczonego pomiędzy okładkami kondensatora, wyrażającą stosunek jego przenikalności dielektrycznej do przenikalności dielektrycznej w próżni $\varepsilon_{o}$ i będącą wielkością stałą.

Rys. 2. Geometria kondensatora

Fig. 2. Geometry of condenser

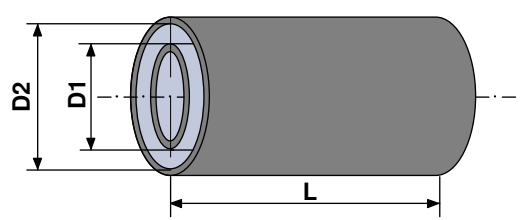

Ponieważ stała dielektryczna paliwa lotniczego (np. Jet-A, Jet A-1, JP-5, JP-8) w temperaturze $20^{\circ} \mathrm{C}$ jest około $2,12 \pm 1,5 \%$ razy większa niż powietrza (pusty zbiornik), to wypełnianie kondensatora pomiarowego paliwem powoduje 
proporcjonalny do poziomu napełnienia zbiornika wzrost jego pojemności elektrycznej. Pojemność elektryczna nadajników paliwomierza w danym zbiorniku jest przetwarzana na zależną od niej liniowo wartość napięcia w bloku elektroniki paliwomierza BEPPM-1. Następnie na podstawie objętościowych charakterystyk zbiorników zapisanych w pamięci mikroprocesora w bloku BEPPM-1 jest cyfrowo wyliczana bieżąca ilość (masa) paliwa w każdym ze zbiorników, z uwzględnieniem kompensacji zmian stałej dielektrycznej. Pojemności elektryczne kompletu nadajników umieszczonych w poszczególnych kanałach pomiarowych wynoszą przy pustych zbiornikach od ok. $70 \mathrm{pF}$ dla dodatkowych zbiorników skrzydłowych do ok. $310 \mathrm{pF}$ dla zbiorników głównych. Wobec tak niskiej wartości przewody łączące nadajniki z blokiem elektronicznym, których długość wynosi kilkadziesiąt metrów, muszą być starannie zaekranowane w celu wyeliminowania wpływu ich pojemności na pomiar. Przykładowo, pojemność nieekranowanej pary przewodów o przekroju $0,35 \mathrm{~mm}^{2} \mathrm{w}$ zależności od wzajemnej odległości między nimi wynosiłaby ok. $10 \div 40 \mathrm{pF}$ na każdy metr długości.

Każdy wyprodukowany komplet paliwomierza musi spełniać wymagania określone w warunkach technicznych. Jego wskazania muszą być możliwie bliskie rzeczywistej masie paliwa, jaką wskaże paliwomierz po zamontowaniu na pokładzie samolotu. Do precyzyjnego wzorcowania służą potencjometry regulacyjne w kanale pomiarowym każdego zbiornika. Podczas wzorcowania następuje kompensacja rozrzutu wartości elementów w bloku elektroniki, a także drobnych różnic w napięciach odniesienia i parametrach przebiegów elektrycznych używanych podczas pomiaru pojemności oraz w wykonaniu i skuteczności ekranowania wiązek elektrycznych.

Teoretycznie $\mathrm{w}$ trakcie wzorcowania paliwomierza nadajniki można byłoby zastąpić kondensatorami o odpowiednio dobranych pojemnościach. Jednak wobec małych wartości tych pojemności stwarza to poważne utrudnienia niepozwalające na uzyskanie wymaganej dokładności (tolerancja pomiarów, wpływ rodzaju i ułożenia przewodów pomiarowych). Po podłączeniu do paliwomierza dobranego w zastępstwie kondensatora wskazanie będzie też nieco inne niż $\mathrm{z}$ nadajnikiem, na co mają wpływ pojemności rozproszone. Aby uzyskać wysoką dokładność paliwomierza, konieczne jest więc przeprowadzanie wzorcowania na stanowisku laboratoryjnym, które pozwoli zapewnić warunki pracy nadajników i ich połączeń jak najbliższe warunkom rzeczywistym.

\section{Stanowisko laboratoryjne paliwomierza}

Paliwomierze lotnicze dla większych statków powietrznych są urządzeniami projektowanymi ,na miarę”. Konieczna jest więc współpraca z konstruktorami konkretnego obiektu latającego z co najmniej dwóch powodów: paliwomierz powinien możliwie wiernie wskazywać ilość paliwa w zbiornikach, ale nie może mieć negatywnego oddziaływania na urządzenia pokładowe statku, na 
którym jest zabudowany. Rozwiązania wymaga jeszcze jeden problem: jak w warunkach laboratoryjnych udowodnić, że zaprojektowane lub produkowane urządzenie spełnia założone wymagania. Jak już wspomniano, elementy paliwomierza, w szczególności nadajniki i sygnalizatory, są rozmieszczone na płatowcu w ściśle określony sposób. W związku z tym głównym zadaniem stanowiska laboratoryjnego musi być wierne odtworzenie rzeczywistych warunków pracy urządzenia. Dwa główne problemy do rozwiązania to odwzorowanie w przestrzeni geometrycznego położenia nadajników i odwzorowanie wzajemnych połączeń elektrycznych. Ponieważ w omawianym paliwomierzu nadajniki są miernikami poziomu paliwa i są mocowane prostopadle do powierzchni skrzydła o aerodynamicznym profilu, ich położenie względem lustra paliwa jest inne dla każdego nadajnika w skrzydle. Ideowo najprostszym rozwiązaniem byłoby ustawienie $\mathrm{w}$ laboratorium skrzydeł samolotu $\mathrm{z}$ rzeczywistymi zbiornikami. Byłoby to rozwiązanie bardzo kosztowne, wymagające dużego pomieszczenia, olbrzymich ilości paliwa, czasochłonnego procesu napełniania i opróżniania zbiorników oraz spełnienia kłopotliwych wymogów przeciwpożarowych i przeciwwybuchowych. Znając zasadę pracy paliwomierza, można ominąć te niedogodności.

Stanowisko laboratoryjne musi wiernie odtwarzać warunki pracy wszystkich nadajników na pokładzie samolotu. Z zasady działania nadajnika, w którym zewnętrzny cylinder spełnia rolę ekranu, wynika, że jego wskazanie nie zależy od rozmiarów zbiornika, w którym jest zanurzony. Wobec tego dla każdego z dwudziestu nadajników poziomu paliwa i dwóch sygnalizatorów reszty paliwa zaprojektowano osobne zbiorniki w kształcie walców, o minimalnej średnicy i długości zapewniającej ich zabudowę, co w efekcie pozwoliło na ograniczenie całkowitej ilości niezbędnego paliwa do kilkudziesięciu litrów. Poszczególne zbiorniki połączono $\mathrm{w}$ odpowiednie grupy, zapewniając $\mathrm{w}$ nich przy napełnianiu i opróżnianiu zmiany poziomu warunki identyczne $\mathrm{z}$ tymi panującymi w rzeczywistych zbiornikach samolotu. Podobnie jak w płatowcu samolotu, w stoisku zasymulowano zbiorniki (rys. 3.):

- rozchodowy lewy i prawy (wyodrębnione w zbiornikach głównych), w których są zabudowane nadajniki poziomu paliwa NP-3, NP-4 i sygnalizatory reszty paliwa SRP-1,

- główny lewy i prawy, w których są zabudowane nadajniki poziomu paliwa NP-5, NP-6, NP-7, NP-8,

- centropłatu lewy i prawy, w których są zabudowane nadajniki poziomu paliwa NP-1, NP-2,

- skrzydłowy dodatkowy lewy i prawy, w których są zabudowane nadajniki poziomu paliwa NP-9, NP-10.

Wysokości ustawienia nadajników na stanowisku i ich kąty pochylenia względem „lustra” paliwa są identyczne z parametrami w zbiornikach samolotu. Do kompensacji zmian stałej dielektrycznej zależnej od właściwości paliwa i jego temperatury służą dodatkowe kondensatory, konstrukcyjnie zabudowane 
w nadajnikach NP-3. Do pomiaru aktualnego poziomu paliwa w wybranym zbiorniku stanowiska służy rurka pomiarowa z podziałką, łączona z tym zbiornikiem za pomocą zaworów hydraulicznych. W stanie ustalonym możliwe jest określenie poziomu z dokładnością do $\pm 0,5 \mathrm{~mm}$.

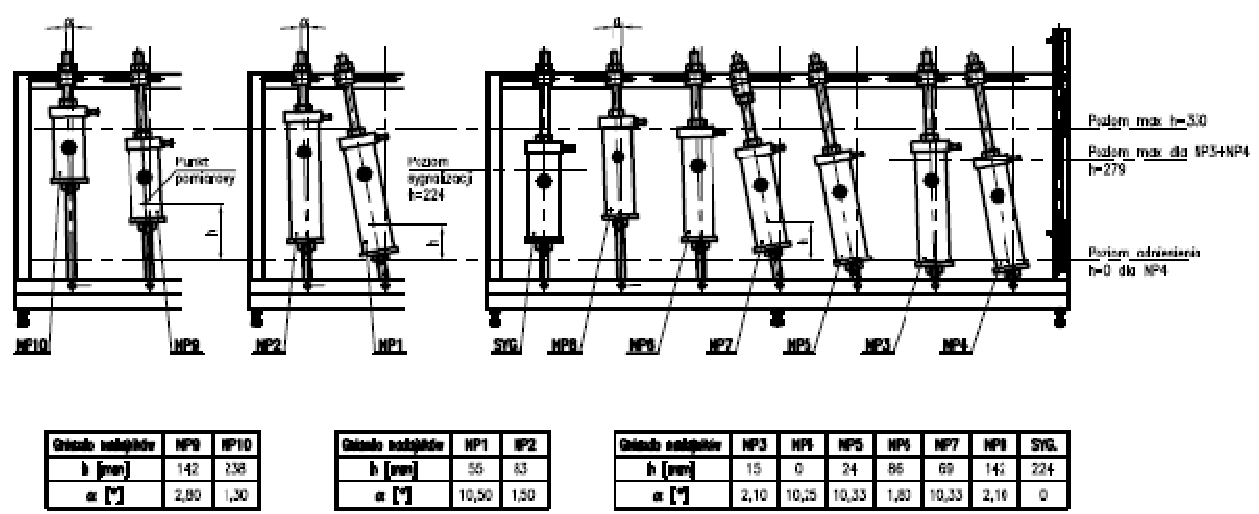

Rys. 3. Rozmieszczenie nadajników paliwomierza PPM-1 w stoisku

Fig. 3. The arrangement of PPM-1fuel gauge transmitters in the stand

Wiązki przewodów łączące na płatowcu poszczególne podzespoły paliwomierza mają dziesiątki metrów długości, w tym olbrzymią liczbę przewodów pomiarowych prowadzonych bezpośrednio w paliwie, oraz kilkudziesięciożyłowe wiązki analogowo-cyfrowe między blokiem elektronicznym a wskaźnikami [2]. Gdy wykonano podobne wiązki łączące podzespoły na stanowisku laboratoryjnym, nie uzyskano wystarczającej zgodności pomiędzy wskazaniami paliwomierza na stanowisku i na pokładzie samolotu. Zastosowanie w wiązce laboratoryjnej typowych rozwiązań niwelujących wpływ zakłóceń, spadków napięć, sprzężeń między przewodami, takich jak: ekranowanie, skręcanie par przewodów, dodatkowe umasienia, nie podniosło wystarczająco powtarzalności wskazań. W związku z tym (w odróżnieniu od użycia rzeczywistych zbiorników samolotu, które było niemożliwe) rozwiązaniem było zastosowanie na stanowisku oryginalnych, pokładowych wiązek samolotu z wszystkimi przepustami i pośrednimi złączami. W celu wyeliminowania wszelkich różnic wiązki zostały wykonane przez producenta samolotu. Na stanowisku ekrany przewodów i obudowy wszystkich podzespołów muszą być połączone z masą zasilania paliwomierza. Ekranowanie i umasienia muszą być wykonane starannie i w sposób trwały, ponieważ każda zmiana rezystancji połączenia może objawiać się znaczną różnicą wskazań.

Paliwomierz PPM-1 jest wyposażony w układ umożliwiający dopasowanie do charakterystyk zbiorników konkretnego egzemplarza samolotu. Pozwala on na skompensowanie indywidualnych różnic wskazań związanych z poziomem 
zamocowania nadajników, nieznacznym wpływem kształtu zbiorników, drobnymi różnicami w wykonaniu i przebiegu wiązek elektrycznych. Wzorcowaniu na stanowisku laboratoryjnym (rys. 4.) podlegają zarówno paliwomierze nowe, jak i paliwomierze sprawdzane okresowo lub naprawiane przez Organizację Obsługową Instytutu Lotnictwa. Paliwomierz po umieszczeniu na stanowisku wzorcuje się w dwóch punktach pomiarowych dla każdego zbiornika, tj. całkowicie opróżnionego i pełnego. Wzorcowanie polega na regulacji w bloku elektroniki ,zera” i ,skali” każdego wewnętrznego napięcia, które jest liniową funkcją poziomu napełnienia kompletu nadajników obsługujących odpowiedni zbiornik. Podczas wzorcowania przy zerowym poziomie paliwa przyjmuje się tylko ujemną tolerancję błędu ustawienia napięcia, tak aby w praktyce uniknąć sytuacji, gdy paliwo skończy się fizycznie przed zejściem wskazań paliwomierza do zera. Po przeprowadzeniu wzorcowania stanowisko jest używane każdorazowo do przeprowadzania prób zdawczo-odbiorczych kompletu paliwomierza. Podczas tych prób w trakcie spuszczania paliwa kolejno z każdego zbiornika wykonuje się sprawdzanie dokładności wskazań paliwomierza w wielu punktach pomiarowych. Budując stanowisko, dołożono wszelkich starań, aby możliwie wiernie odwzorowywało rzeczywisty samolot. Paliwomierz po laboratoryjnej procedurze skalowania wymaga już tylko niewielkich regulacji po zabudowie w płatowcu.

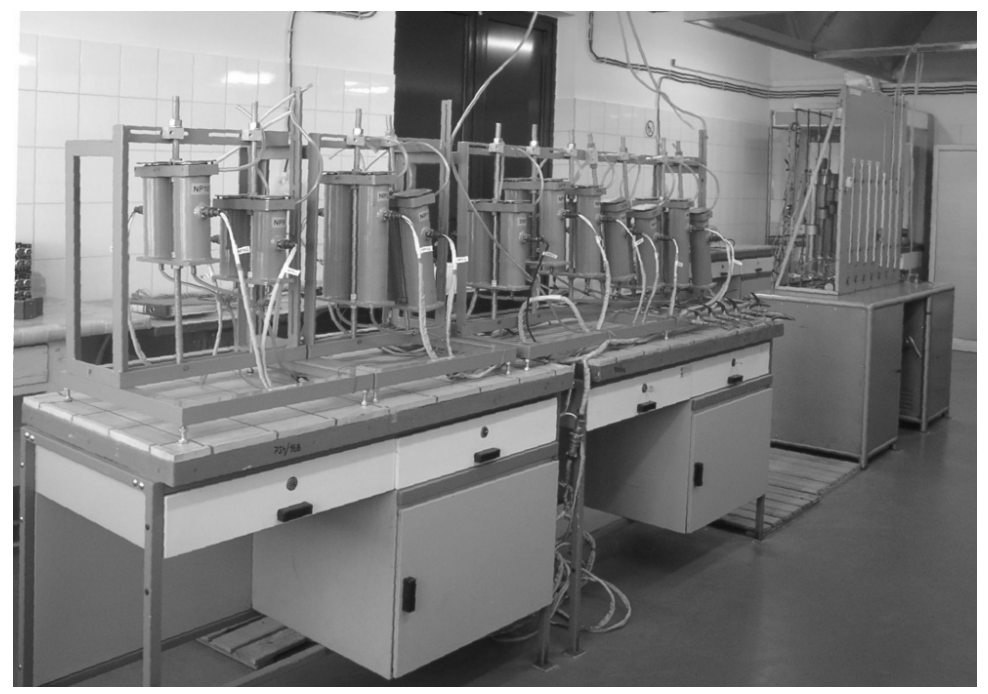

Rys. 4. Widok stanowiska laboratoryjnego paliwomierzy PPM-1

Fig. 4. The view of the laboratory stand of PPM-1 fuel gauges

Paliwomierz PPM-1 mierzy ilość paliwa w jednostkach masowych [lbs, $\mathrm{kg}$ ]. Ponieważ wartości wzorcowe wskazań wykorzystywane w urządzeniu są określone dla normalnych warunków otoczenia, pomieszczenie, w którym znaj- 
duje się stanowisko, musi charakteryzować się określoną w warunkach technicznych stabilną temperaturą. Również używane paliwo musi spełniać określone wymagania. Powodem niedokładności wzorcowania może być błąd odczytu poziomu paliwa na podziałce, a w szczególności zjawisko paralaksy i menisku wklęsłego paliwa w rurce pomiarowej. Należy też zwrócić uwagę na odpowietrzenie stanowiska, ponieważ ewentualne pęcherzyki powietrza powodują, że odczytywany poziom paliwa różni się od poziomu w zbiorniku. Źródłem błędów może być też rozregulowanie poziomów ustawienia i kątów pochylenia zbiorników stanowiska, zmiana parametrów połączeń elektrycznych oraz zmiana (z biegiem czasu) właściwości paliwa (stałej dielektrycznej). Błędy te mogą narastać podczas eksploatacji, a są eliminowane podczas wymaganej, okresowej legalizacji stanowiska.

\section{Podsumowanie}

Zaprojektowane i wykonane w Instytucie Lotnictwa laboratoryjne stanowisko paliwomierzy PPM-1 sprawdziło się zarówno na etapie opracowania, badania prototypów, jak też produkcji i weryfikacji eksploatowanych paliwomierzy. Zastosowanie stanowiska pozwoliło na znaczne skrócenie i uproszczenie uciążliwych prac z użyciem paliwa, zapewniając przy tym możliwość sprawdzenia i diagnostyki wszystkich parametrów paliwomierza w pełnym zakresie zmian poziomu paliwa w zbiornikach samolotu. W trakcie dotychczasowej, kilkunastoletniej eksploatacji z jego wykorzystaniem przewzorcowano i sprawdzono dziesiątki kompletów paliwomierzy typu PPM-1.

\section{Literatura}

[1] Langton R., Clark C., Hewitt M., Richards L.: Aircraft fuel systems. J. Wiley \& Sons, Oxford 2009.

[2] Młynarczyk M., Mrotek Z.: Wybrane problemy pomiaru ilości paliwa w zbiornikach statków powietrznych, [w:] Wybrane zagadnienia awioniki, red. Jan Gruszecki. Oficyna Wydawnicza Politechniki Rzeszowskiej, Rzeszów 2011, 103-112.

[3] Młynarczyk M., Mrotek Z.: Testowanie i diagnostyka paliwomierzy typu PPM-1 z wykorzystaniem testera TPPM-1. Zeszyty Naukowe Politechniki Rzeszowskiej 213, Mechanika z. 63, 2004.

[4] Kaźmierski J., Młynarczyk M., Mrotek Z.: Mikroprocesorowy pomiar masy paliwa w zbiornikach statku powietrznego metodą pomiaru pojemności. Zeszyty Naukowe Politechniki Rzeszowskiej 186, Mechanika z. 56, 2001.

[5] Babiasz E., Kaźmierski J., Młynarczyk M., Mrotek Z.: Cyfrowy system pomiaru ilości paliwa PPM-1. Zeszyty Naukowe Politechniki Rzeszowskiej 186, Mechanika z. 56, 2001. 


\title{
PROBLEMS OF REPRESENTATION OF THE REAL AIRCRAFT FUEL TANKS CHARACTERISTICS IN LABORATORY CONDITIONS
}

\begin{abstract}
Information about the quantity of fuel remained in aircraft tanks is especially important for a safe flight. Considering complicated shapes and the number of tanks, a built-up and compound measuring system it is necessary to ensure required accuracy. A special laboratory test stand, that exactly represents real aircraft fuel tanks characteristics, must be constructed for each type of aircraft fuel measuring systems to be calibrated or inspected. This paper presents problems that had to be solved by constructors of the laboratory stand made for the M-28 aircraft PPM- 1 fuel measuring system. Relationship between particular stand elements and on-board fuel transmitters installed inside fuel tanks, as well as bundles used for electrical connections has been described. The article also presents principles of the capacitance method of fuel mass measurement and the manner of calibrating the measuring set. In the end authors name some factors that can disturb measurements or affect their accuracy.
\end{abstract}

Keywords: aircraft fuel tank, fuel gauge, flight safety

DOI: $10.7862 / \mathrm{rm} .2013 .28$

Otrzymano/received: 15.09 .2013

Zaakceptowano/accepted: 22.10 .2013 